\title{
Papers
}

\section{Planning for death but not serious future illness: qualitative study of housebound elderly patients}

\author{
Joseph A Carrese, Jamie L Mullaney, Ruth R Faden, Thomas E Finucane
}

\begin{abstract}
Objective To understand how elderly patients think about and approach future illness and the end of life. Design Qualitative study conducted 1997-9.

Setting Physician housecall programme affiliated to US university.

Participants 20 chronically ill housebound patients aged over 75 years who could participate in an interview. Participants identified through purposive and random sampling.

Main outcome measures In-depth semistructured interviews lasting one to two hours.

Results Sixteen people said that they did not think about the future or did not in general plan for the future. Nineteen were particularly reluctant to think about, discuss, or plan for serious future illness. Instead they described a "one day at a time," "what is to be will be" approach to life, preferring to "cross that bridge" when they got to it. Participants considered end of life matters to be in the hands of God, though 13 participants had made wills and 19 had funeral plans. Although some had completed advance directives, these were not well understood and were intended for use only when death was near and certain.

Conclusions The elderly people interviewed for this study were resistant to planning in advance for the hypothetical future, particularly for serious illness when death is possible but not certain.
\end{abstract}

\section{Introduction}

Planning in advance is widely encouraged as a way to improve quality of care at the end of life. ${ }^{1}$ Cross cultural studies have shown that healthcare providers and patients often differ in their views on health related matters. ${ }^{2-5}$ The willingness to consider future illness and the end of life, for example, is not universal; patients in some communities are reluctant to consider or speak about such matters. ${ }^{67}$ We asked a group of chronically ill elderly patients about their views on advance planning of care.

\section{Methods}

We carried out a focused ethnographic study ${ }^{8}$ within a care programme for elderly people in east Baltimore, United States. For the past 20 years this programme has provided medical and nursing care to generally frail housebound elderly people (mean age 77 years) in a largely working class community. At any given time there are about 180 active patients in the programme. Most patients are white $(148,82 \%)$ and female (124, $69 \%)$. About 169 patients (94\%) in the programme have Medicare and $31(17 \%)$ have Medicaid. Patients are referred to the programme by physicians who do not visit patients at home and by home nurses. Patients are eligible for the programme if they require an ambulance to attend a clinic and live in the catchment area for the medical centre. They are not otherwise selected and are generally typical of older, chronically ill people living in the community in the United States. Home visits are made by attending physicians, fellows in geriatric medicine, or general internal medicine residents. Multidisciplinary care, which may involve nurse visits, various therapists (physical, occupational, and speech), and home health aides, is facilitated through a programme coordinator and weekly team meetings.

\section{Sampling}

We identified participants through purposive and random sampling. ${ }^{9}$ Patients in the care programme were chosen as the study population because they represented chronically ill patients with a high mortality (about 45 patients or $25 \%$ per year). ${ }^{10}$ They therefore have experience with and must often make decisions about illness and the end of life. Once we had identified a suitable population of patients we randomly selected individuals to reduce bias.

Exclusion criteria included age less than 75 , factors that would preclude a meaningful interview (such as cognitive impairment, aphasia, profound hearing impairment, language barriers), participation in pilot interviews, and impending out of system transfer.

We enrolled seven participants (three white women, two white men, one black woman, one black man) in the first year (1997-8) and 13 (ten white women, one white man, two black women) in the second year. We continued enrolling participants until no new concepts arose in the interviews - that is, when the point of redundancy was achieved.

\section{Measurements}

One of us (JAC) conducted in-depth semistructured baseline interviews that lasted one to two hours with each patient. An interview guide was used as a starting

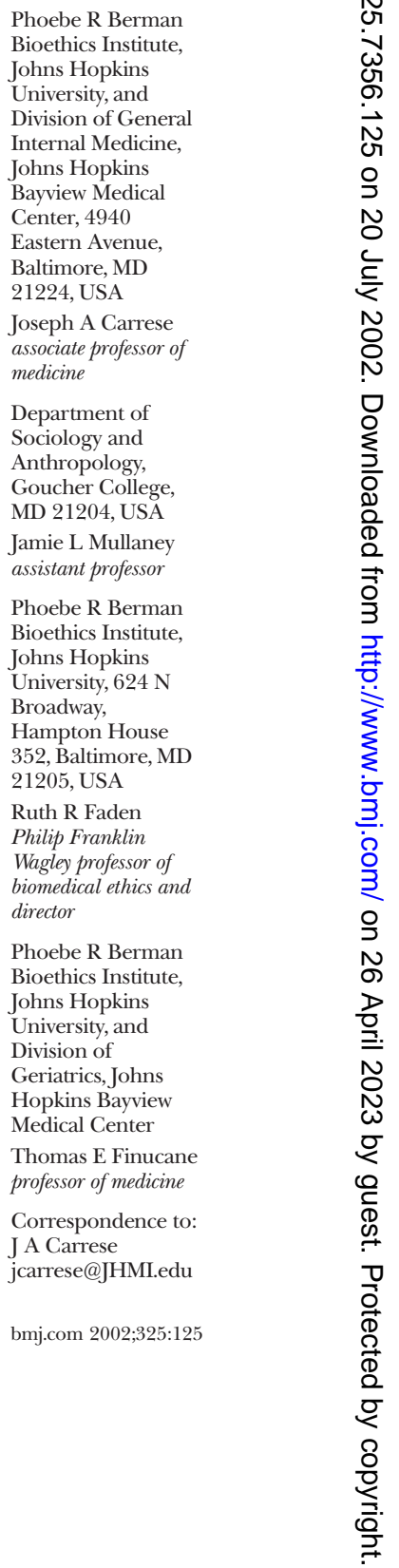


Table 1 Demographic information on participants and non-participants

\begin{tabular}{lcc} 
Characteristics & Participants $\mathbf{( n = 2 0 )}$ & Non-participants $(\mathbf{n}=\mathbf{1 1})$ \\
\hline Mean (median) age (years) & $86(86)$ & $85(84)$ \\
\hline Median age at leaving school (years) & 14 & 14 \\
\hline White/black & $16 / 4$ & $8 / 3$ \\
\hline Women/men & $16 / 4$ & $5 / 6$ \\
\hline Mean (median) health status (1-5) & $3.3(3)$ & $3.0(3)$ \\
\hline Mean (median) religiousness (1-5)† & $3.2(3)$ & $3.8(4)$
\end{tabular}

${ }^{*}$ Self reported, $5=$ excellent health.

†Self reported, $5=$ extremely religious.

point for the interviews (box). Participants were given considerable latitude to comment on points or topics they considered relevant. We collected demographic information on all patients.

\section{Analysis}

Interviews were audiotaped, transcribed, independently coded by two readers (JAC, JLM), and compared for agreement. We used an editing style analysis ${ }^{11}$ : the transcripts were read and interpreted "naively" (that is, without a preconceived template) as we tried to understand participants and accurately represent their stated views.

Because of the duration of the interviews and the latitude granted to participants we generated a large amount of data in these baseline interviews. The findings that we have presented in this paper, a portion of the complete data set, were selected by an iterative process that included all members of the study team in various ways. We used the qualitative research software program NUD*IST 4. We analysed comparisons between participants and those who declined to participate using Fisher's exact test and the Wilcoxon rank sum test.

At least two investigators participated in each step of the analysis (for example, reading and coding transcripts, identification, modification, conceptual organisation of categories, and selection of themes and representative quotes for presentation). All decisions were made by consensus. We reviewed and checked findings from the baseline interviews for accuracy during follow up interviews, some of which were conducted by a second investigator (JLM).

The study was approved by the Johns Hopkins Bayview Medical Center Institutional Review Board. We obtained written informed consent from all study participants.

\section{Interview guide (subset of full guide)}

Regarding future illness and end of life care

- Is this something you should think about and discuss with others? Have you?

- Is this something you should plan for or have planned for?

- If you become so ill that you are unable to make decisions about your medical care how will doctors and family members know what to do for you?

- If you do not prefer to plan for future illness and end of life care, how then do you think about these issues? Do you have an alternative approach for addressing future illness and the end of life?

\section{Results}

We invited 31 people to participate and enrolled 20. Table 1 gives demographic information on participants and non-participants. Participants had limited formal education, most were white women, and they considered themselves to be in fair health and moderately religious. Those who declined to participate did not differ in any of the demographic characteristics.

Table 2 gives additional information about participants. As a group their mental status was fair, they were not depressed, and despite being housebound their functional limitations were modest, averaging dependence in 1.5 out of six activities of daily living.

The core focus of these interviews was to elicit and understand participants' views about planning for future illness and end of life. We have presented the five themes that we considered from the interviews to be most closely tied to this core focus.

\section{Considering the future}

Although we asked participants to comment about future illness, 16 responded initially by describing how they regarded the future in general. These participants were particularly reluctant to think about, plan for, or, in some cases, even acknowledge the future. For many patients these were lifelong views; others had adopted these attitudes as they became older and infirm. This was an unexpected finding on a topic about which we had not specifically asked. The comments of an 83 year old man with diabetes who was living with his wife in their family home were typical: "Well, I don't think of it. I am not interested in the future. I just take what comes. I have always done that and that is how I feel about it... How do I know what is going to happen then or how I am going to feel about it then? I don't have that kind of intelligence. I mean, who knows what is going to happen in the future? I would rather not be asked about what is going to happen even tomorrow."

A few participants shared concerns about losing their independence and becoming a burden in the future. A few others identified specific goals for the near future, such as improvement in their medical condition or their living arrangements, even if these hoped for outcomes were unrealistic. These remarks show a limited sense of the future.

\section{Contingencies of serious future illness}

Some participants were comfortable thinking about, discussing, and planning for the contingencies of serious future illness, but most were quite resistant. While many participants did not offer a specific reason, others offered various explanations for why they were resistant to such planning. Some were simply not ready to do it; others believed it couldn't be done successfully, was associated with substantial uncertainty, could be

Table 2 Additional characteristics of participants

\begin{tabular}{lcc} 
Characteristics & Possible score & Mean (range) score \\
\hline Mental status $^{*}$ & $0-10$ & $2(0-6)$ \\
\hline Depression screen $\dagger$ & $0-15$ & $3.8(1-14)$ \\
\hline Function $\ddagger$ & $0-6$ & $1.4(0-5)$ \\
\hline
\end{tabular}

*Short portable mental status exam: 0-2=intact, 3-4=mild intellectual impairment, 5-7=moderate intellectual impairment, 8-10=severe intellectual impairment.

†Geriatric depression scale, short form: normal $=0-5$; $>5$ suggests depression. ¥Katz index of independence in activities of daily living: bathing, dressing, going to toilet, transfer, continence, feeding; $6=$ dependent in all six domains. 
upsetting, or had the potential to cause bad things to happen. A 76 year old woman with chronic obstructive pulmonary disease who depended on oxygen said: "I can't answer that because I don't want to face that yet... I'll put it this way to you: I'm too young to worry about something like that. That's the best answer I can give you. When the time comes, then I'll worry. I don't want to hear it... If you dwell on it, then you have a problem ... you can make yourself miserable. I think you can. I look outside. I see the sun ... I don't look ahead five, ten years from now. I look at my life today as it goes on. And again, when I get older, yeah, I might start worrying. [JC: How old are you now?] 76. Too young for that"

Most participants were resistant to planning because they considered these matters to be God's domain. God, in this view, is in control of what happens in the future and at the end of life, and it is not the individual's role to be concerned about these matters or to plan actively for them. An 87 year old woman living with a friend of the family in their trailer home said: "No one is gonna know but the good Lord what is gonna happen in the future ... He knows when $\mathrm{He}$ is gonna take you away from this old world, I think ... I'll let the Lord take care of me. [JAC: But these bigger decisions about what happens] I don't think there is gonna be such big decisions ... I think the Lord is just gonna take me some night in my sleep ... I think God knows when He should take control. [JAC: What does that leave for you to do?] Pray and be ready to meet Him."

Once these views were established the interviewer explained to participants the rationale for advance planning and urged them to consider the predicament of doctors trying to make decisions about treatment in the absence of information about patient preferences. While most participants did not alter their views, after repeated questioning a subgroup (six of the 19) said they would be willing to listen and perhaps talk with doctors about these issues, although several remained ambivalent. A 91 year old man's response was characteristic of this subgroup: "Well, what good is it going to do me, number one. If it ain't gonna do me no good, I don't want to hear it. [JAC: Well, what if I said that the good it might do you is that they would have a better understanding of what you would want, your choices, your preferences?] Well, maybe I would listen to it. I know they can't do miracles for me... when old people are ready to go the only thing they can do for you is try to make you feel happy as long as you are here."

\section{Living in the present}

As we learnt about their views towards the future and future planning, we asked patients how they approached these issues and life in general. Most participants described a "one day at a time," "what is to be will be" approach to life that was compatible with their views about the future. An 84 year old woman living alone in retirement apartments said: "I just take it from day to day ... I don't know what is going to happen tomorrow cause tomorrow is not promised to you ... You live from day to day, you don't worry about tomorrow ... tomorrow never comes sometimes ... Today is the day, not tomorrow."

An 89 year old blind woman also living alone in retirement housing said: "What is to be will be. That's the way I got it now. [JAC: "When you were younger would you plan for things that would happen in the future?] Yeah, I used to think 'oh, if this don't happen, that don't happen', right? Now I don't think about it no more ... Whatever happens is going to happen. I don't look for it to come, you know?"

Many patients articulated a preference to "cross that bridge" of making decisions about possible serious future illness only when they had to-that is, when confronting those issues in real time. This seems to be a specific application of the more general "one day at a time" philosophy. An 80 year old recently widowed woman who was confined to a wheelchair said she didn't have any concerns regarding future illness: "I don't have any, I mean, why worry about it? What's going to happen is going to happen and I believe in crossing that bridge when you get to it, you know."

\section{Final arrangements for death}

Curiously, despite most of these people not thinking about or planning for the future, many had made "final arrangements" for their death. Thirteen of 19 had made a will, and 19 had funeral plans or cemetery plots. An 85 year old woman whose husband and four children had died said "I have got everything paid for. My stone ... my grave ... everything. We had that done, both of us, long before he died."

\section{Advance directives}

Some participants had completed an advance directive: seven had designated a healthcare agent, and 11 had completed a living will. But only five had completed and even minimally understood the healthcare agent form, and only six had completed and even minimally understood the living will. Furthermore, these directives were intended for use in narrow circumstances, such as when death was near and certain. A 76 year old women said: "A living will is I don't want to be hooked up to machinery to save my life ... Because I don't want my life to be prolonged. When my time is up, I want to die."

\section{Views of the future}

Our participants seemed to divide the future into three distinct segments, which they approached differently: firstly, an uncertain contingent future that may be accompanied by chronic and serious illness, ${ }^{12}$ which they are generally unwilling to plan for or even contemplate; secondly, a time when death is near and certain, which they are somewhat more likely to plan for and discuss; and thirdly, the event of death itself and what follows, for which they are likely to have made arrangements.

\section{Discussion}

Our findings contrast with a central tenet of good care at the end of life: that physicians and patients should make plans in advance about possible future illness. ${ }^{13}$ The elderly people we interviewed described a world view that does not easily accommodate such advance planning. Their general stance is to live life "day to day" and to approach future problems by "crossing that bridge when they get to it." They resist suggestions to conceive, discuss, and plan about the hypothetical future. And they show deference to God in guiding events near the end of life. Although limitations ${ }^{14}{ }^{15}$ and proposed modifications ${ }^{16}{ }^{17}$ of the advance planning 
model have been reported, our findings have not been described previously. It is notable that while departures from conventional thinking might be expected in cross cultural settings, the participants we interviewed were predominantly non-hispanic white people.

Some of these people may be persuaded to participate in advance planning. Those who defer to God might, with the involvement of clergy, agree to revise their thinking and have a more active role in facing the future along with God. For some, designating a healthcare agent might be a partial solution, even for those unwilling to discuss the relevant issues with their agents. Many people are willing to accept decisions their agents make, even if these decisions differ from their previously stated preferences. ${ }^{18} 19$

Some people, however, will simply resist the idea that they should think about and discuss future states that include severe illness and provide guidance about decisions that might arise. This may not be a matter of barriers that can be overcome or attitudes that can evolve. A blinkered insistence that such patients participate in advance care planning would probably be fruitless.

The views of these people highlight a central difficulty in planning for "end of life care." Our patients were least likely to envision and help to plan for a period of chronic serious illness when death is not certain. It is precisely in this interval that the most difficult decisions often arise: patients must choose between a burdensome treatment that offers the chance of longer life or a more palliative course that offers less suffering but at the cost of dying sooner. ${ }^{20}$ In the interval when death is near and certain and these decisions are becoming simpler our patients were somewhat more willing to help to decide in advance. In their view advance directives apply to this more hopeless situation. Our patients do plan for the certain future. They know that one day they will be dead, and arrangements have been made for that day.

\section{Limitations of study}

We interviewed only a relatively small number of people, and as a group they were elderly, ill, housebound, and had limited formal education. The findings may not apply to other populations with different characteristics. A second limitation is the possibility of "social desirability bias." Participants might have provided what they considered to be "acceptable" responses to the physician interviewer. If this were the case, we might expect the expressed views to be more in line with the medical model; we did not observe this.

A major strength of our study is that by using a qualitative approach we encountered unexpected findings: these patients were not readily willing to contemplate and exert control over events in the hypothetical future. We believe that we succeeded in understanding some of the perspectives of our participants, which was the main goal of the study.

Our findings do not argue against advance care planning; rather, they identify additional limitations to the conventional model for making decisions about serious future illness. As the literature in cross cultural medicine has made clear, no single approach is likely to work for all patients. Our study shows that scrupulous attempts to plan about care in advance will
What is already known on this topic

Advance care planning is widely endorsed as a means to improve quality of care for patients near the end of life

\section{What this study adds}

Elderly housebound patients described a world view that does not easily accommodate advance care planning: they live life a day at a time, preferring not to consider problems until they occur

These patients resisted planning for the hypothetical future

They most resisted planning for those situations when the most difficult decisions often arise, such as for serious illness when death is possible but not certain

not, in all cases, solve the problem of decision making for seriously ill and incapacitated patients.

We thank Dr Diener-West for assistance with statistical analysis. This paper was presented at the Society of General Internal Medicine Annual meeting in Boston, May 2000, and at the American Society for Bioethics and Humanities Annual meeting in Salt Lake City, October 2000.

Contributors: JAC had the original idea for the project, was the principle investigator, and is guarantor. JAC, RRF, and TEF contributed to the conception and design of the project. JAC conducted the baseline interviews; JAC and JLM conducted follow up interviews. JAC, JLM, and TEF read and coded the transcripts. JLM entered data into a qualitative research software program. JAC and JLM developed and revised the categories of themes; TEF critically reviewed these findings for coherence and completeness. JAC wrote the manuscript, with contributions from TEF. JLM, TEF, and RRF critically reviewed the paper and suggested revisions. All authors approved the final version of the paper.

Funding: Robert Wood Johnson Generalist Physician Faculty Scholars Program, Johns Hopkins Bayview Physicians Education and Research Fund.

Competing interests: None declared.

1 Lynn J. Measuring quality of care at the end of life: a statement of principles. J Am Geriatr Soc 1997;45:526-7.

2 Perez-Stable EJ, Sabogal F, Otero-Sabogal R, Hiatt RA, McPhee SJ

Misconceptions about cancer among Latinos and Anglos. JAMA 1992;268:3219-23.

1992;268:3219-23.
Perkins HS, Supik JD, Hazuda HP. Autopsy decisions: the possibility of conflicting cultural attitudes. J Clin Ethics 1993;4:145-54.

4 McKinley ED, Garrett JM, Evans AT, Davis M. Differences in end-of-life decision making among black and white ambulatory cancer patients. $J$ Gen Intern Med 1996;11:651-6.

5 Hern HE Jr, Koenig BA, Moore LJ, Marshall PA. The difference that culture can make in end-of-life decisionmaking. Camb Q Healthc Ethics 1998;7:27-40

6 Carrese JA, Rhodes LA. Western bioethics on the Navajo reservation. Benefit or harm? JAMA 1995:274:826-9.

7 Carrese JA, Rhodes LA. Bridging cultural differences in medical practice The case of discussing negative information with Navajo patients. J Gen Intern Med 2000; 15:92-6.

8 Muecke MA. On the evaluation of ethnographies. In: Morse J, ed. Critical issues in qualitative research methods. Beverly Hills: Sage, 1993:198-9.

9 Bernard H. Russell. Research methods in anthropology: qualitative and quantitative approaches. 2nd ed. Walnut Creek: Altimira Press, 1994:95-6.

10 Tsuji I, Whalen S, Finucane TE. Predictors of nursing home placement in community-based long-term care. J Am Geriatr Soc 1995;43:761-6.

11 Crabtree BF, Miller WL. Doing qualitative research. Newbury Park: Sage, 1992:18.

12 Lynn J, Forlini JH. "Serious and complex illness" in quality improvement and policy reform for end-of-life care.J Gen Intern Med 2001;16:315-9.

13 Cassel CK, Field MJ, eds. Approaching death. Improving care at the end of life. Washington, DC: National Academy Press, 1997:139-40.

14 Curtis JR Patrick DL. Barriers to communication about end-of-life care in AIDS patients. J Gen Intern Med 1997;12:736-41.

15 Pfeifer MP, Sidorov JE, Smith AC, Boero JF, Evans AT, Settle MB. The discussion of end-of-life medical care by primary care patients and 
physicians: a multicenter study using structured qualitative interviews. $J$ Gen Intern Med 1994;9:82-8.

16 Rosenfeld KE, Wenger NS, Kagawa-Singer M. End-of-life decision making: a qualitative study of elderly individuals. J Gen Intern Med 2000;15:620-5.

17 Martin DK, Thiel EC, Singer PA. A new model for advance care planning: observation from people with HIV. Arch Intern Med 1999;159:86-92.

18 Sehgal A, Galbraith A, Chesney M, Schoenfeld P, Charles G, Lo B. How strictly do dialysis patients want their advance directives followed? JAMA 1992;267:59-63.
19 Terry PB, Vettese M, Song J, Forman J, Haller KB, Miller DJ, et al. End-oflife decision making: when patients and surrogates disagree. J Clin Ethic 1999;10:286-93.

20 Finucane TE. How gravely ill becomes dying: a key to end-of-life care. JAMA. 1999;282:1670-2.

(Accepted 7 February 2002) 